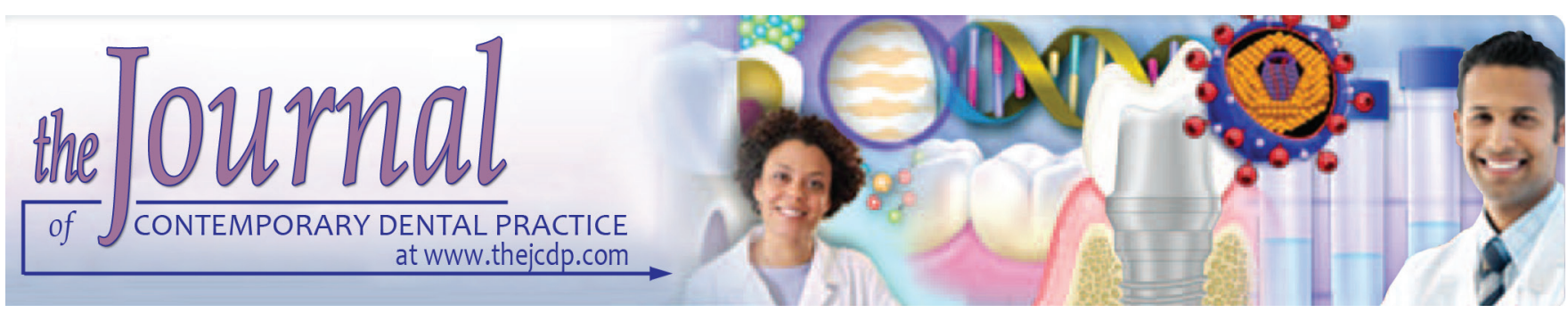

\title{
Assessment of the Pubertal Growth Period using the Open Apices of the Lower Teeth
}

\author{
${ }^{1}$ Yousef N Issa, ${ }^{2}$ Ahmad S Burhan, ${ }^{3}$ Fehmieh R Nawaya, ${ }^{4}$ Lama G Massouh
}

\begin{abstract}
Aim: The purpose of this study was to evaluate whether the open apex measurements of the lower teeth can be used for prediction of the pubertal growth spurt.
\end{abstract}

Materials and methods: The study group consisted of 150 males and 142 females ranging in age from 10 to 16 years. A total of 292 panoramic and 292 hand-wrist radiographs were obtained and analyzed. The skeletal maturity was determined according to the skeletal maturity indicators (SMIs) developed by Fishman. The open apices measurements of the left lower teeth were made according to the method described by Cameriere.

Results: The Spearman rank order correlation coefficient revealed a relationship between the skeletal maturity stages and the open apex measurements. These correlations ranged from 0.577 for the lower second premolar to 0.830 for the lower canine. The measurement of the left lower canine showed the highest correlation, so its relationship with the SMls was further investigated. The measurements of 6.07 (or greater) indicated to SMI4, and 2.485 (or lesser) indicated to SMI7.

Conclusion: The skeletal maturity well related to the measurements of the open apices of the lower teeth. Lower canine open apex measurements could be used as an indicator of the SMI4 and SMI7.

Clinical significance: The measurements of the open apices of the left lower canines from panoramic radiographs may be clinically useful as an indicator of the beginning and the ending of the pubertal growth period.

Keywords: Hand-wrist radiographs, Lower canine, Lower teeth, Open apices, Panoramic radiographs, Pubertal growth period.

\footnotetext{
1,2Department of Orthodontics, Damascus University, Damascus Syrian Arab Republic

${ }^{3}$ Department of Pediatric Dentistry, Syrian Private University Damascus Countryside, Syrian Arab Republic

${ }^{4}$ Department of Biochemistry and Microbiology, Damascus University, Damascus, Syrian Arab Republic

Corresponding Author: Ahmad S Burhan, Department of Orthodontics, Damascus University, Damascus, Syrian Arab Republic, e-mail: dr.burhan-a@hotmail.com
}

How to cite this article: Issa YN, Burhan AS, Nawaya FR, Massouh LG. Assessment of the Pubertal Growth Period using the Open Apices of the Lower Teeth. J Contemp Dent Pract 2017;18(1):16-22.

\section{Source of support: Nil}

Conflict of interest: None

\section{INTRODUCTION}

The importance of skeletal maturation concept, which refers to the potential growth, comes from the wide variation in the rate of progress of individuals toward physiologic maturity. ${ }^{1}$ This concept makes it possible for orthodontists to assess both the amount and velocity of facial growth, and consequently to achieve a correct diagnosis and treatment planning. This assessment is a mandatory perquisite, especially in cases which entail orthopedic correction, extraoral traction for growth modification, extraction vs nonextraction, the type of retention, and orthognathic surgery timing., ${ }^{2,3}$

The techniques used in the assessment of bone maturation depended on visual scrutiny of the developing bones of different areas of the skeleton, such as the foot, the elbow, the hip, the ankle, the cervical vertebrae, and the hand-wrist, with the last one being the favorable choice for bone age assessment. ${ }^{4,5}$ On the other hand, exposing the patient to extra radiation dose to predict the pubertal growth spurt is considered not necessary and should be avoided. ${ }^{6}$ Many alternatives, which depend on the routine diagnostic records, have been suggested like the frontal sinus, ${ }^{7}$ the cervical vertebrae, ${ }^{8}$ and dental development. Dental maturity is an indicator of the biologic age. Many attempts have been made trying to identify the dental development stages using panoramic images, which are routinely required in orthodontic cases. Some of these attempts used the absolute length measurements of teeth like Gleiser and Hunt method, ${ }^{9}$ Nolla method, ${ }^{10}$ Moorrees et al method. ${ }^{11}$ Others are based on the relative value 
of crown height to roots length of teeth like Demirjian system. This system is simple, enables more reliable standardization, and has good reproducibility and inter/intra reliability. ${ }^{12}$ However, it has some inherent disadvantages; in addition to that, the examiner has to subjectively estimate and fit a tooth into one of specified schematic models of development stages, the period between these stages is long, and may cover more than one skeletal stage. Moreover, if the tooth is tipped into the buccolingual direction, the early-stage evaluation of dental development will be underestimated. ${ }^{13}$ In several studies conducted by Cameriere et al, ${ }^{14}$ a new approach to assess the dental development has been created, which is based on measuring the degree of apical completeness of roots through liner millimetric measurements of the open apices of the lower teeth. Instead of classifying them into stages, a regression formulae deriving age have been developed. ${ }^{14-18}$ The most important advantage of this method is the elimination of subjective estimation of dental maturation. ${ }^{14}$

This investigation aimed to detect the degree of skeletal maturation using panoramic radiographs. Therefore, it assessed the relationship between the measurements of the open apices of the lower teeth and the skeletal maturity indicators (SMIs). This should lead to reduce the radiation dose needed during orthodontic diagnosis, and economically benefit patients.

\section{MATERIALS AND METHODS}

This study was designed as an observational analytical cross-sectional research. The sample was derived from dental panoramic and hand-wrist radiographs (soft and hard copies) of 150 males and 142 females registered as patients at the Orthodontic Department, Faculty of Dentistry, Damascus University. These radiographs were taken as parts of routine treatment records between October 2009 and December 2015.

\section{Inclusion Criteria}

The subjects included in the study were all Syrians with normal overall growth and development, and with chronological age ranged from 10 to 16 years. The panoramic and hand-wrist radiographs were taken within an interval of 1 month at maximum.

\section{Exclusion Criteria}

Subjects with incomplete records or low-quality pretreatment panoramic or hand-wrist radiographs; abnormal dental conditions, such as impaction, transposition, and congenitally missing teeth; subjects with any developmental endocrine or nutritional disorders; subjects with history of trauma or injury to the face or hand and wrist regions or patients who had undergone to previous orthodontic treatment or permanent tooth extraction have been excluded from the study.

\section{Sample Size Estimation}

To calculate the required sample size, $G^{*}$ Power software, version 3.0.6 (Franz Faul, Universität Kiel, Germany), was used with the following inputs: A power study of $85 \%$; number of groups of 8; a significance level of 5\%; an effect size of 0.25 ; and with a statistical test of one-way analysis of variance (ANOVA). The required sample size was 264 subjects (33 cases in each group).

\section{Assessment of the Skeletal and Dental Maturity}

All the soft copies of the radiographs were stored in a computer and examined using MiViewer software, version 8.1.0 (MILLENSYS, Egypt).

Skeletal maturation, using the rating of SMIs, was determined according to the method described by Fishman. ${ }^{19}$ He has divided 11 skeletal maturation indicators into three subgroups: 1 to 4 represent periods of accelerating growth velocity, 4 to 7 represent periods of exceptionally high growth rate, 7 to 11 corresponds to decelerating growth velocity. ${ }^{20}$ In the current study, only patients who belong to one of the following SMIs were included because these periods cover the pubertal growth spurt: SMI 4, which is based on the ossification of the adductor sesamoid of the thumb (S) (34 males, 32 females), SMI 5, which is based on the capping of the epiphysis of the distal phalanx of the 3rd finger (DP3cap) (40 males, 38 females), SMI 6, which is based on the capping of the epiphysis of the middle phalanx of the 3rd finger (MP3cap) (46 males, 40 females), SMI 7, which is based on the capping of the epiphysis of the middle phalanx of the 5th finger (MP5cap) (30 males, 32 females).

Dental maturation was assessed by measuring the open apices according to the method of Cameriere et al. ${ }^{14}$ Only the left lower teeth with incomplete roots excluding the 3rd molars were considered (canines, 1st and 2nd premolars, 2nd molars). This selection was because the apical closure of the upper and lower incisors and 1st molars had already occurred. On the contrary, most studies have omitted the upper posterior teeth because the superimposition of calcified structures in this area results in inaccurate evaluation of dental development. ${ }^{5,21-26}$ The distance between the inner sides of each open apex (A) was measured. To take into account the effect of possible differences in magnification and angulation among X-rays, the measurements were normalized by dividing A to the tooth length (L) and multiplied with 100 (Fig. 1).

To prevent the observer bias, all panoramic and hand-wrist radiographs were coded with numerical 


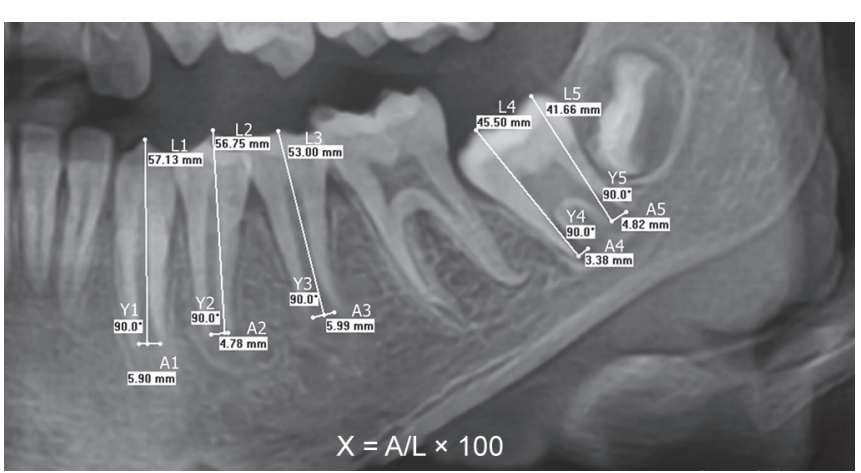

Fig. 1: Measurements of the open apices according to the method of Cameriere et al. A is the distance between the inner sides of the open apex, $L$ is the tooth length (the distance between the farthest point on the tooth crown and segment $A$ ), and $Y$ is the angle between A and $\mathrm{L}$, which is $90^{\circ}$

identifications. Then, these radiographs were blindly evaluated by one investigator (YI) who was not aware of the name, age, or sex of the patients during evaluation of the records.

All data (SMIs and normalized measurements of open apices of the studied teeth) and the subjects' name and gender were entered into an EXCEL sheet after matching the numerical identifications with the patients' names.

\section{Statistical Analysis}

The data were analyzed using the Statistical Package for the Social Sciences (SPSS) software, version 20, (IBM Corp., Armonk, New York, USA).

Kolmogorov-Smirnov test was used to test the normality of distribution. It indicated that the sample did not come from a normally distributed population. Mann-Whitney test was used to evaluate the existence of sexual dimorphism in the SMIs and in the normalized measurements of the open apices. Spearman rank order correlation coefficient was used to measure the association between the SMIs and the normalized measurement of open apices of each individual tooth.

Kruskal-Wallis test was used to test the differences in the open apices measurements between the groups of the SMIs. Mann-Whitney test was used to reflect the differences between each two groups of the SMIs.

Sensitivity and specificity were determined for each SMI and the relevant open apex measurement for each one of the studied SMIs (S, DP3cap, MP3cap, MP5cap). Then, the curve of receiver operating characteristic (ROC) was created for each maturation stage.

\section{Accuracy Test of MiViewer Software}

Twenty randomly selected panoramic radiographs were viewed on a viewing box and the various liner measurements were manually and blindly made by the same
YI (distance $\mathrm{A}$ and $\mathrm{L}$ ), and the $\mathrm{X}$ value was gained as explained previously. The paired sets of measurements carried out on the reexamined 20 panoramic radiographs were statistically tested using Wilcoxon test, which shows insignificant differences between the manual and digital measurements.

\section{Reproducibility Test}

To test the reproducibility of the assessments of skeletal maturity and dental development, the YI blindly reevaluated randomly selected hand-wrist and panoramic radiographs of 20 males and 20 females 1 month after the first evaluation. The differences between double interpretations were statistically tested to evaluate the intraobserver agreement using Kappa test for the skeletal maturation stages and the intraclass correlation coefficient for the open apices measurements. These tests showed a perfect agreement between the 1st and 2nd assessments.

\section{RESULTS}

The sample of the current study included 292 adolescent males and females ranging in age from 10 to 16 years. This sample was divided into eight groups according to the stage of skeletal maturation and gender as shown in Table 1. Table 2 presents the descriptive statistics; the

Table 1: Distribution of the sample according to the stages of skeletal maturation and gender

\begin{tabular}{|c|c|c|c|c|c|c|}
\hline \multirow{3}{*}{$\begin{array}{l}\text { Skeletal } \\
\text { maturation } \\
\text { stage }\end{array}$} & \multicolumn{6}{|c|}{ Number of subjects } \\
\hline & \multicolumn{2}{|c|}{ Males } & \multicolumn{2}{|c|}{ Females } & \multicolumn{2}{|c|}{ Total } \\
\hline & $n$ & $\%$ & $n$ & $\%$ & $n$ & $\%$ \\
\hline S & 34 & 11.65 & 32 & 10.95 & 66 & 22.60 \\
\hline DP3cap & 40 & 13.70 & 38 & 13.00 & 78 & 26.71 \\
\hline MP3cap & 46 & 15.76 & 40 & 13.69 & 86 & 29.45 \\
\hline MP5cap & 30 & 10.28 & 32 & 10.95 & 62 & 21.23 \\
\hline Total & 150 & 51.4 & 142 & 48.6 & 292 & 100 \\
\hline
\end{tabular}

$\mathrm{N}$ : Number; \%: Percentage; S: The stage based on the ossification of the adductor sesamoid of the thumb; DP3cap: The stage based on the capping of the epiphysis of the distal phalanx of the 3rd finger; MP3cap: The stage based on the capping of the epiphysis of the middle phalanx of the 3rd finger; MP5cap: The stage based on the capping of the epiphysis of the middle phalanx of the 5th finger

Table 2: Descriptive statistics for each tooth according to the method of Cameriere et al

\begin{tabular}{lllll}
\hline & $\begin{array}{l}\text { Number of } \\
\text { subjects }\end{array}$ & Mean & $\begin{array}{l}\text { Standard } \\
\text { deviation }\end{array}$ & $\begin{array}{l}\text { Standard } \\
\text { error }\end{array}$ \\
\hline Lariables & 292 & 5.02 & 4.12 & 0.34 \\
Lower left canine & 292 & 4.95 & 5.39 & 0.45 \\
Lower left 1st premolar left 2nd premolar & 292 & 9.67 & 14.98 & 1.24 \\
$\begin{array}{l}\text { Mesial root of the } \\
\text { lower left 2nd molar }\end{array}$ & 292 & 5.15 & 3.61 & 0.30 \\
$\begin{array}{l}\text { Distal root of the lower } \\
\text { left 2nd molar }\end{array}$ & 292 & 8.43 & 4.94 & 0.41 \\
\hline
\end{tabular}


Table 3: Differences between males and females in the skeletal maturation stages and the measurements of open apices

\begin{tabular}{lcc}
\hline Variables & $U_{\text {-value }}$ & p-value \\
\hline $\begin{array}{l}\text { Skeletal maturation stages } \\
\begin{array}{l}\text { Open apex measurement of lower left } \\
\text { canine }\end{array}\end{array}$ & 2626.0 & $0.882^{-}$ \\
$\begin{array}{l}\text { Open apex measurement of lower left } \\
\text { 1st premolar }\end{array}$ & 2656.0 & $0.055^{-}$ \\
$\begin{array}{l}\text { Open apex measurement of lower left } \\
\text { 2nd premolar }\end{array}$ & 2456.0 & $0.418^{-}$ \\
$\begin{array}{l}\text { Open apex measurement of the mesial root } \\
\text { of the lower left 2nd molar }\end{array}$ & 2523.0 & $0.585^{-}$ \\
$\begin{array}{l}\text { Open apex measurement of the distal root } \\
\text { of the lower left 2nd molar }\end{array}$ & 2324.5 & $0.186^{-}$ \\
\hline a Using Mann-Whitney U-test; 'No significant difference &
\end{tabular}

Table 5: Multiple comparisons in the measurements of the lower canine open apex between the skeletal maturation stages

\begin{tabular}{llll}
\hline $\begin{array}{l}\text { Skeletal maturation } \\
\text { stage }\end{array}$ & $\begin{array}{l}\text { Skeletal maturation } \\
\text { stage }\end{array}$ & U-value & $p$-value \\
\hline S & DP3cap & 231.0 & $<0.001^{* * *}$ \\
& MP3cap & 72.0 & $<0.001^{* * *}$ \\
& MP5cap & 1.0 & $<0.001^{* * *}$ \\
DP3cap & MP3cap & 287.5 & $<0.001^{* * *}$ \\
& MP5cap & 21.0 & $<0.001^{* * *}$ \\
MP3cap & MP5cap & 224.5 & $<0.001^{* * *}$ \\
\hline
\end{tabular}

a Using Mann-Whitney U-test; ${ }^{* * *}$ Statistically significant at the 0.001 level; S: The stage based on the ossification of the adductor sesamoid of the thumb; DP3cap: The stage based on the capping of the epiphysis of the distal phalanx of the 3rd finger; MP3cap: The stage based on the capping of the epiphysis of the middle phalanx of the 3rd finger; MP5cap: The stage based on the capping of the epiphysis of the middle phalanx of the 5 th finger

left lower centrals, laterals, and 1st molars apices were closed in all subjects.

Mann-Whitney U-test indicated no sexual dimorphism as shown in Table 3. Spearman rank order correlation coefficients between the skeletal maturation indicators and the measurements of the five individual open apices of the studied roots are shown in Table 4 . The absolute values of the association ranged from 0.577 to 0.830 . The lower canine was the tooth which showed the highest correlation, so it was chosen to further investigate its relationship with the chosen SMIs.

Kruskal-Wallis test was used to detect differences between skeletal maturation groups. It showed that two groups or more were statistically different ( $\mathrm{p}$-value $<0.001)$. Mann-Whitney U-test was used to further discover the statistically different couple of groups, and showed that there were significant differences between all compared groups (Table 5). Sensitivity and specificity were used to evaluate the diagnostic performance of the lower canine open apex measurements for identifying the skeletal maturation stages of the pubertal growth period. The areas under ROC curves suggested high validity of the lower canine open apex
Table 4: Correlation coefficients (Spearman's rho) between the skeletal maturation stages and the measurements of open apices of each tooth

\begin{tabular}{llll}
\hline & \multicolumn{3}{c}{ Skeletal maturation stages } \\
\cline { 2 - 4 } $\begin{array}{l}\text { Measurements of } \\
\text { open apices }\end{array}$ & $\begin{array}{c}\text { Correlation } \\
\text { coefficient }\end{array}$ & $\begin{array}{l}\text { Number of } \\
\text { subjects }\end{array}$ & $p$-value ${ }^{\mathrm{b}}$ \\
\hline Lower canine & -0.830 & 292 & $<0.001^{\text {***}}$ \\
Lower 1st premolar & -0.680 & 292 & $<0.001^{\text {***}}$ \\
Lower 2nd premolar & -0.577 & 292 & $<0.001^{\text {***}}$ \\
mesial root of the lower & -0.607 & 292 & $<0.001^{\text {***}}$ \\
2nd molar & & & \\
$\begin{array}{l}\text { Distal root of the lower } \\
\text { 2nd molar }\end{array}$ & -0.645 & 292 & $<0.001^{\text {*** }}$ \\
\hline
\end{tabular}

bUsing the correlation coefficient (Spearman's rho); ${ }^{* * *}$ Statistically significant at the 0.001 level

Table 6: Areas under the receiver operating characteristic curve based on the measurements of the lower canine open apex in the different skeletal maturation stages

\begin{tabular}{|c|c|c|c|}
\hline $\begin{array}{l}\text { Skeletal maturation } \\
\text { stage }\end{array}$ & $\begin{array}{l}\text { Area under } \\
\text { ROC curve }\end{array}$ & $\begin{array}{l}\text { Standard } \\
\text { error }\end{array}$ & $p$-value \\
\hline $\mathrm{S}$ & 0.918 & 0.024 & $<0.001^{* * *}$ \\
\hline DP3cap & 0.673 & 0.044 & $<0.001^{* * *}$ \\
\hline MP3cap & 0.331 & 0.045 & $<0.001^{* * *}$ \\
\hline MP5cap & 0.069 & 0.021 & $<0.001^{* * *}$ \\
\hline
\end{tabular}

*** Statistically significant at the 0.001 level; S: The stage based on the ossification of the adductor sesamoid of the thumb; DP3cap: The stage based on the capping of the epiphysis of the distal phalanx of the 3rd finger; MP3cap: The stage based on the capping of the epiphysis of the middle phalanx of the 3rd finger; MP5cap: The stage based on the capping of the epiphysis of the middle phalanx of the 5th finger; ROC: Receiver operating characteristic

measurements in determining the (S) and the (MP5cap) stages, and low validity in determining the (DP3cap) and (MP3cap) stages (Graphs 1A to D and Table 6). The optimal combination of sensitivities and specificities and the optimal cut-off values for lower canine open apex measurements to dichotomize each of the four skeletal maturation stages are presented in Table 7 .

\section{DISCUSSION}

Many researchers have studied the relationship between the skeletal maturity and dental development, but the literature shows contradictory results. Some authors found that the dental development is a reliable indicator of the skeletal maturity, $5,21,23,24$ while others found that the dental development is of limited value in identifying stages of the skeletal maturity. ${ }^{22,25-28}$ Perinetti et al ${ }^{22}$ found that dental development is only useful in diagnosis of the prepubertal growth phase. Goyal et $\mathrm{a}^{25}$ reported that only the onset and the accelerating phase of the pubertal growth period can be predictable. Morris and Park $^{28}$ recommended using the dental development as a rough estimation only to skeletal maturation. Malik et al ${ }^{26}$ demonstrated that the usefulness of dental development 

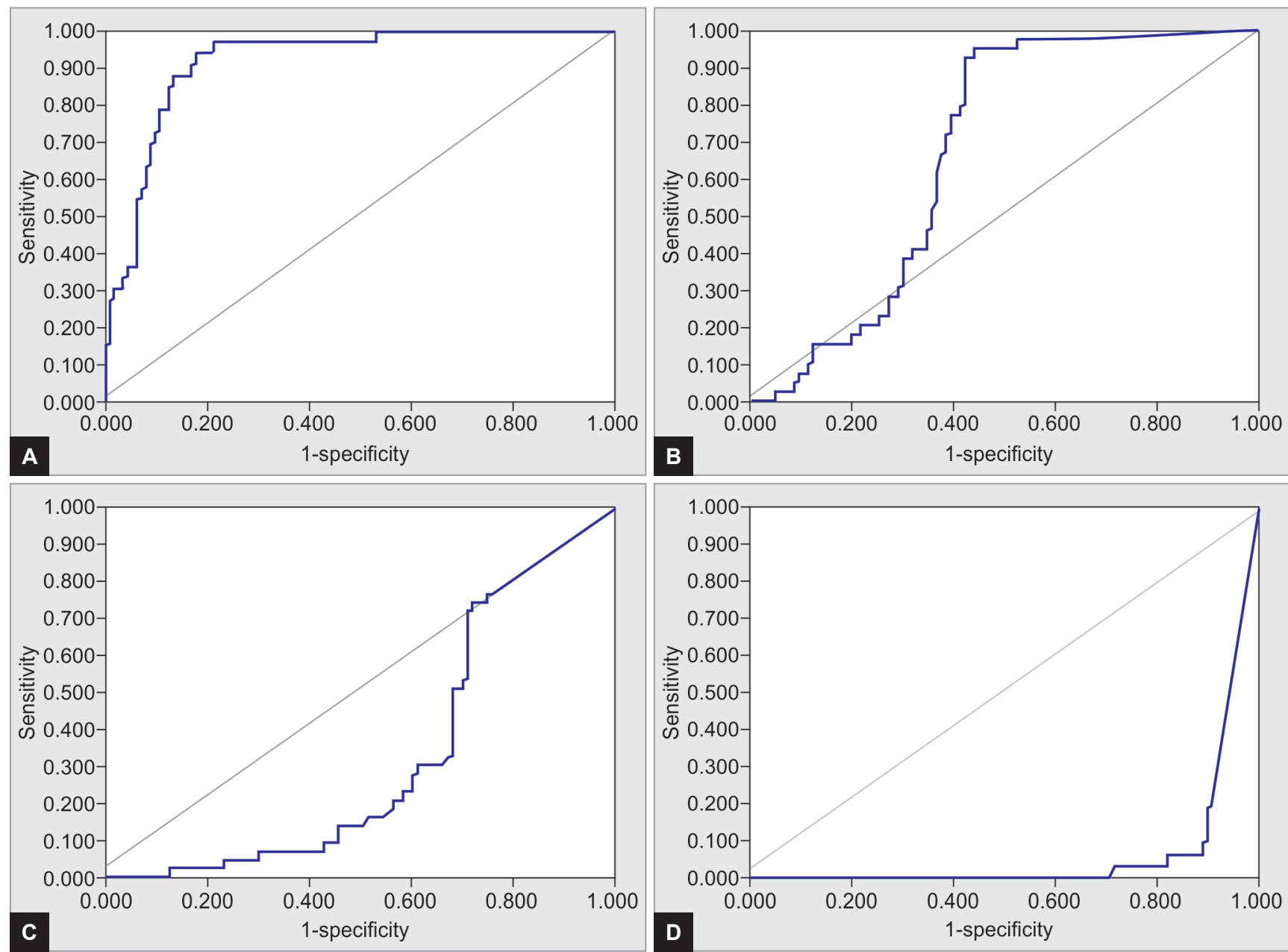

Graphs 1A to D: Receiver operating characteristics curves for the lower canine open apex measurements to discriminate the skeletal maturation stages: (A) (S); (B) (DP3cap); (C) (MP3cap); and (D) (MP5cap)

Table 7: Sensitivity and specificity values for the measurements of the lower canine open apex in the different skeletal maturation stages

\begin{tabular}{|c|c|c|c|c|}
\hline $\begin{array}{l}\text { Skeletal } \\
\text { maturation } \\
\text { stage }\end{array}$ & Rule & $\begin{array}{l}\text { Open apex } \\
\text { measurement } \\
\text { of the lower } \\
\text { canine (cut- } \\
\text { off value) }\end{array}$ & Sensitivity & Specificity \\
\hline$S$ & $\begin{array}{l}\text { Greater than } \\
\text { or equal }\end{array}$ & $\geq 6.07$ & 0.939 & 0.823 \\
\hline DP3cap & $\begin{array}{l}\text { Greater than } \\
\text { or equal }\end{array}$ & $\geq 4.365$ & 0.949 & 0.561 \\
\hline MP3cap & $\begin{array}{l}\text { Less than } \\
\text { or equal }\end{array}$ & $\leq 5.245$ & 0.837 & 0.544 \\
\hline MP5cap & $\begin{array}{l}\text { Less than } \\
\text { or equal }\end{array}$ & $\leq 2.485$ & 0.935 & 0.887 \\
\hline
\end{tabular}

S: The stage based on the ossification of the adductor sesamoid of the thumb; DP3cap: The stage based on the capping of the epiphysis of the distal phalanx of the 3rd finger; MP3cap: The stage based on the capping of the epiphysis of the middle phalanx of the 3rd finger; MP5cap: The stage based on the capping of the epiphysis of the middle phalanx of the 5 th finger

is limited to some age groups only. Chertkow ${ }^{27}$ found it useful with Caucasian children, but with caution with other racial groups. Some researchers did not recommend using the dental maturity to assess the treatment timing in spite of the correlation between the dental and skeletal development. ${ }^{29,30}$ This contradictory may be explained by variant approaches used in evaluating the skeletal and dental maturity. Most studies used the hand-wristbased systems ${ }^{23,24,26,27}$ or the cervical vertebrae-based systems ${ }^{21,22,25,29}$ in evaluating the skeletal maturation stage. Racial variation may also contribute to the controversy in results. ${ }^{5,23,27}$

The skeletal maturity assessment in the current study was based on the method described by Fishman. ${ }^{19}$ Many wnized and simple approach, and it is recommended for clinical and research purposes. ${ }^{19}$ In addition, it is one of the methods detecting the relative growth velocity and percentage of growth remaining. Therefore, it is more helpful than other approaches producing a skeletal age. ${ }^{2}$

The open apex approach is based on objective measurements of open apices and teeth lengths, and applies a continuous scale of development. Also, little experience is needed by dentists to perform it. This method was used previously to evaluate the chronological age, and the results indicated its accuracy and suitability. ${ }^{14-18}$ To our knowledge, the current investigation is the first study that try to analyze the relationship between the skeletal maturity and the open apices of developing teeth, and 
utilize this approach in predicting the skeletal maturation stages. Racial variations affect the relationship between skeletal and dental development. ${ }^{27}$ Unfortunately, no previous study dealing with this field has been applied on a Syrian sample.

In the current study, no statistically significant sexual dimorphism was noted for both skeletal and dental development indicators. This result was similar to the one obtained by Jatti et $\mathrm{al}^{31}$ when open apices approach was used in an Indian sample to evaluate the lower left teeth. Also, the current findings were supported by Rai et $\mathrm{al}^{32}$ who used the open apices approach to predict the chronological age in an Indian sample and concluded that gender is not a significant variable when formulating the predicting regression formula.

Contrary to our results, Krailassiri et $\mathrm{al}^{5}$ found a significant difference between males and females in a Thai sample when evaluating skeletal maturity according to Fishman ${ }^{19}$ and the lower teeth development according to Demirjian system. ${ }^{12}$ Sahin Sağlam and Gazilerli ${ }^{30}$ also differentiated between males and females when presenting the results of correlation between skeletal maturity according to Fishman ${ }^{19}$ and Demirjian dental development stages ${ }^{12}$ of upper and lower canines, premolars, and lower 2nd molar in Turkish subjects. Uysal et $\mathrm{al}^{23}$ indicated that sex differences were also noted in the pattern of bone maturation assessment according to Björk $^{33}$ and Grave and Brown ${ }^{34}$ and mineralization of lower teeth according to Demirjian method ${ }^{12}$ in a Turkish sample. Likewise, Lopes et $\mathrm{al}^{24}$ observed a difference between the sexes in the skeletal maturation periods according to Grave and Brown ${ }^{34}$ and in mineralization stages of the lower teeth according to Demirjian method ${ }^{12}$ in a Brazilian sample. When open apices approach was applied to predict the chronological age, many studies on different races showed that gender has a significant influence on age estimation, so boys and girls were analyzed separately on Italian samples, ${ }^{14,35}$ a European sample, ${ }^{15}$ a Chinese sample, ${ }^{36}$ and a South Indian sample. ${ }^{31}$ In addition to the differences in the approaches used in evaluating skeletal and dental development, these variations may be explained by racial variations of the samples.

In the current study, the absolute values of the correlation coefficients between the studied SMIs and normalized open apex values of each of the lower teeth were high, ranging from 0.577 to 0.830 , and were statistically significant $(p<0.001)$. The lower canine showed the highest correlation between the SMIs and its development assessed by open apex method. These findings are in line with those of Chertkow and Fatti ${ }^{37}$ who found that root formation completion of the lower canine prior to apical closure was strictly related to the calcification of the adductor sesamoid bone, but that was low for the remaining teeth. Also, Coutinho et $\mathrm{al}^{38}$ found that the relationship between the calcification stages of the lower canine according to Demirjian method ${ }^{12}$ and the skeletal maturation phase according to Tanner et $\mathrm{al}^{39}$ was quit high, ranging from 0.53 to 0.85 in an American sample.

Contrary to our results, Krailassiri et $\mathrm{al}^{5}$ found that the lower 2nd premolar and the lower 2nd molar development stages according to Demirjian ${ }^{12}$ and the SMIs according to Fishman ${ }^{19}$ have the highest correlation in Thai individuals. They attributed their findings to the apical closure of most canines and first premolars in the MP3cap and DP3cap stages for males and females respectively. In addition, the results of Uysal et $\mathrm{al}^{23}$ showed that the sequence in order of the highest to the lowest correlation was 2nd molar, 2nd premolar, 1st molar, canine, 3rd molar. Their study assessed the skeletal maturation according to Björk ${ }^{33}$ and Grave and Brown, ${ }^{34}$ and the dental development according to Demirjian ${ }^{12}$ in Turkish subjects. The diversity in methodology used in assessing the skeletal and dental development, age range, sample size, and the ethnicities may be the reason behind the controversy in results.

\section{CONCLUSION}

- No sexual dimorphism was noted for all the studied skeletal and dental indicators.

- The correlation between skeletal maturity stages and the measurements of open apices of the lower teeth were high and differed for each individual tooth, ranging from 0.577 for the lower 2nd premolar to 0.830 for the lower canine.

- Lower canine open apex measurements could be used clinically as an indicator of the (S) and (MP5cap) stages only, but could not be used to indicate the (DP3cap) and (MP3cap) stages.

\section{CLINICAL SIGNIFICANCE}

Beginning and ending of the pubertal growth period can be predictable using the measurements of open apices of the left lower canines from panoramic radiographs. This diagnostic procedure can be fulfilled without resorting to hand-wrist radiographs, which reduces the exposure to radiation during orthodontic treatment.

\section{REFERENCES}

1. Chen J, Hu H, Guo J, Liu Z, Liu R, Li F, Zou S. Correlation between dental maturity and cervical vertebral maturity. Oral Surg Oral Med Oral Pathol Oral Radiol Endod 2010 Dec;110(6):777-783.

2. Flores-Mir C, Nebbe B, Major PW. Use of skeletal maturation based on hand-wrist radiographic analysis as a predictor of facial growth: a systematic review. Angle Orthod 2004 Feb;74(1):118-124. 
3. Bagherpour A, Pousti M, Adelianfar E. Hand skeletal maturity and its correlation with mandibular dental development. J Clin Exp Dent 2014 Jul;6(3):e275-e279.

4. Manzoor Mughal A, Hassan N, Ahmed A. Bone age assessment methods: a critical review. Pak J Med Sci 2014 Jan;30(1):211-215.

5. Krailassiri S, Anuwongnukroh N, Dechkunakorn S. Relationships between dental calcification stages and skeletal maturity indicators in Thai individuals. Angle Orthod 2002 Apr;72(2):155-166.

6. Turpin DL. British Orthodontic Society revises guidelines for clinical radiography. Am J Orthod Dentofacial Orthop 2008 Nov;134(5):597-598

7. Ruf S, Pancherz H. Frontal sinus development as an indicator for somatic maturity at puberty? Am J Orthod Dentofacial Orthop 1996 Nov;110(5):476-482

8. Baccetti T, Franchi L, McNamara JA Jr. An improved version of the cervical vertebral maturation (CVM) method for the assessment of mandibular growth. Angle Orthod 2002 Aug;72(4):316-323.

9. Gleiser I, Hunt EE Jr. The permanent mandibular first molar: its calcification, eruption and decay. Am J Phys Anthropol 1955 Jun;13(2):253-283.

10. Nolla CM. The development of the permanent teeth. J Dent Child 1960;27(4):254-266.

11. Moorrees CF, Fanning EA, Hunt EE Jr. Age variation of formation stages for ten permanent teeth. J Dent Res 1963 Nov-Dec;42:1490-1502.

12. Demirjian A, Goldstein $H$, Tanner JM. A new system of dental age assessment. Hum Biol 1973 May;45(2):211-227.

13. Mörnstad H, Staaf V, Welander U. Age estimation with the aid of tooth development: a new method based on objective measurements. Scand J Dent Res 1994 Jun;102(3):137-143.

14. Cameriere R, Ferrante L, Cingolani M. Age estimation in children by measurement of open apices in teeth. Int J Legal Med 2006 Jan;120(1):49-52.

15. Cameriere R, DeAngelis D, Ferrante L, Scarpino F, Cingolani M. Age estimation in children by measurement of open apices in teeth: a European formula. Int J Legal Med 2007 Nov;121(6): 449-453.

16. Cameriere R, Ferrante L, Liversidge HM, Prieto JL, Brkic H. Accuracy of age estimation in children using radiograph of developing teeth. Forensic Sci Int 2008 Apr;176(2-3):173-177.

17. Fernandes MM, Tinoco RL, de Braganca DP, de Lima SH, Francesquini Junior L, Daruge Junior E. Age estimation by measurements of developing teeth: accuracy of Cameriere's method on a Brazilian sample. J Forensic Sci 2011 Nov;56(6): 1616-1619.

18. Galić I, Vodanović M, Cameriere R, Nakaš E, Galić E, Selimović E, Brkić H. Accuracy of Cameriere, Haavikko, and Willems radiographic methods on age estimation on BosnianHerzegovian children age groups 6-13. Int J Legal Med 2011 Mar;125(2):315-321.

19. Fishman LS. Radiographic evaluation of skeletal maturation. A clinically oriented method based on hand-wrist films. Angle Orthod 1982 Apr;52(2):88-112.

20. Fishman LS. Maturational patterns and prediction during adolescence. Angle Orthod 1987 Jul;57(3):178-193.

21. Kumar S, Singla A, Sharma R, Virdi MS, Anupam A, Mittal B. Skeletal maturation evaluation using mandibular second molar calcification stages. Angle Orthod 2012 May;82(3):501-506.

22. Perinetti G, Contardo L, Gabrieli P, Baccetti T, Di Lenarda R. Diagnostic performance of dental maturity for identification of skeletal maturation phase. Eur J Orthod 2012 Aug;34(4):487-492.

23. Uysal T, Sari Z, Ramoglu SI, Basciftci FA. Relationships between dental and skeletal maturity in Turkish subjects. Angle Orthod 2004 Oct;74(5):657-664.

24. Lopes LJ, de Oliveira Gamba T, Visconti MA, Ambrosano GM, Haiter-Neto F, Freitas DQ. Utility of panoramic radiography for identification of the pubertal growth period. Am J Orthod Dentofacial Orthop 2016 Apr;149(4):509-515.

25. Goyal S, Goyal S, Gugnani N. Assessment of skeletal maturation using mandibular second molar maturation stages. J Clin Pediatr Dent 2014 Fall;39(1):79-84.

26. Malik P, Rana V, Rehani U. To evaluate the relationship between mandibular canine calcification stages and skeletal age. Int J Clin Pediatr Dent 2012 Jan;5(1):14-19.

27. Chertkow $S$. Tooth mineralization as an indicator of the pubertal growth spurt. Am J Orthod 1980 Jan;77(1):79-91.

28. Morris JM, Park JH. Correlation of dental maturity with skeletal maturity from radiographic assessment: a review. J Clin Pediatr Dent 2012 Spring;36(3):309-314.

29. Perinetti G, Westphalen GH, Biasotto M, Salgarello S, Contardo L. The diagnostic performance of dental maturity for identification of the circumpubertal growth phases: a meta-analysis. Prog Orthod 2013 May 23;14:8.

30. Sahin Sağlam AM, Gazilerli U. The relationship between dental and skeletal maturity. J Orofac Orthop 2002 Nov;63(6):454-462.

31. Jatti D, Kantaraj Y, Nagaraju R, Janardhan S, Nataraj S. Age estimation by measuring open apices of lower erupted teeth in 12-16 years olds by radiographic evaluation. J Forensic Leg Med 2013 Jul;20(5):430-434

32. Rai B, Kaur J, Cingolani M, Ferrante L, Cameriere R. Age estimation in children by measurement of open apices in teeth: an Indian formula. Int J Legal Med 2010 May;124(3): 237-241.

33. Björk A. Timing of interceptive orthodontic measures based on stages of maturation. Trans Eur Orthod Soc 1972:61-74.

34. Grave KC, Brown T. Skeletal ossification and the adolescent growth spurt. Am J Orthod 1976 Jun;69(6):611-619.

35. Cameriere R, Pacifici A, Pacifici L, Polimeni A, Federici F, Cingolani M, Ferrante L. Age estimation in children by measurement of open apices in teeth with Bayesian calibration approach. Forensic Sci Int 2016 Jan;258:50-54.

36. Guo YC, Yan CX, Lin XW, Zhou H, Li JP, Pan F, Zhang ZY, Wei L, Tang Z, Chen T. Age estimation in northern Chinese children by measurement of open apices in tooth roots. Int J Legal Med 2015 Jan;129(1):179-186.

37. Chertkow S, Fatti P. The relationship between tooth mineralization and early radiographic evidence of the ulnar sesamoid. Angle Orthod 1979 Oct;49(4):282-288.

38. Coutinho S, Buschang PH, Miranda F. Relationships between mandibular canine calcification stages and skeletal maturity. Am J Orthod Dentofacial Orthop 1993 Sep;104(3):262-268.

39. Tanner JM, Whitehouse RH, Marshall WA, Carter BS. Prediction of adult height from height, bone age, and occurrence of menarche, at ages 4 to 16 with allowance for midparent height. Arch Dis Child 1975 Jan;50(1):14-26. 